\title{
ЭФФЕКТИВНОСТЬ ИСПОЛЬЗОВАНИЯ КОМБИНАЦИЙ САХАРИДОВ В СРЕДАХ ДЛЯ КРИОКОНСЕРВАЦИИ СПЕРМЫ ПЕТУХОВ
}

\author{
Ю.Л. СИЛЮКОВА ${ }^{凶}$ О.И. СТАНИШЕВСКАЯ, Н.В. ПЛЕШАНОВ, \\ А.А. КУРОЧКИН
}

Различные комбинации сахаридов могут обеспечить эффективную защиту семени во время цикла замораживания/оттаивания. До настоящего времени дисахарид мальтоза не использовался в качестве компонента среды для криоконсервации семени петухов. Поскольку мальтоза не участвует в углеводном обмене сперматозоидов, есть предположение о ее роли в укреплении структуры гликокаликса. В представленной работе впервые доказана эффективность использования мальтозы в сочетании с фруктозой в составе разбавителя для повышения оплодотворяющей способности заморожено-оттаянного семени петухов. Целью работы было определение оптимальной концентрации мальтозы в составе разбавителя для замораживания семени петухов в возрасте 44-50 нед и установление сроков сохранения функциональной полноценности заморожено-оттаянного семени в половых путях курицы. Эксперимент проводился в ЦКП «Генетическая коллекция редких и исчезающих пород кур» (ВНИИГРЖ) на курах (Gallus gallus L.) породы русская

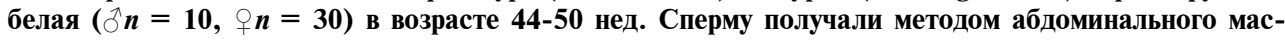
сажа. Оценивали три варианта сред для криоконсервации семени с различным соотношением сахаридов: Mal-10 (фруктоза 0,72 \%, мальтоза 0,166 \%), Mal-20 (фруктоза 0,64 \%, мальтоза $0,326 \%$ и и ЛКС-контроль (Ленинградская криозащитная среда) (фруктоза 0,8 \%, мальтоза 0 \%). Разбавленные образцы семени охлаждали с 18 до $5^{\circ} \mathrm{C}$ в течение 40 мин. Затем к каждому образцу добавляли диметилацетамид до конечной концентрации $6 \%$. Образцы инкубировали при $5{ }^{\circ} \mathrm{C}$ в течение 1 мин. Гранулы замораживали, накапывая семя в жидкий азот. Замороженное семя хранили в жидком азоте в течение 30 сут. Гранулы размораживали по fast-протоколу при $60{ }^{\circ} \mathrm{C}$. Двигательную активность заморожено-оттаянных сперматозоидов оценивали в каждом экстендере с помощью визуализирующей системы CASA (computer-assisted sperm analysis). Для искусственного осеменения отобрали виргинных кур в возрасте 46-50 нед $(n=30$, по $n=10$ в каждой опытной группе). Кур осеменяли интравагинально разовыми суточными дозами 0,04-0,07 мл замороженооттаянного семени: в течение первых 2 сут по одному осеменению, затем одно осеменение каждые 2 сут. Яйца для инкубации собирали ежедневно в течение 9 сут, начиная со следующего дня после первого осеменения. Яйца $(n=239)$ инкубировали 6 сут для оценки фертильности. Яйца, собранные в каждой экспериментальной группе на 5-е, 10-е и 15-е сут после последнего осеменения, разбивали и оценивали оплодотворенность по наличию бластодиска. Динамику функционального состояния заморожено-оттаянных сперматозоидов в половых путях кур определяли на 5-е, 10-е и 15-е сут от последнего осеменения. В вителлиновой мембране подсчитывали отверстия - точки взаимодействия со сперматозоидами. Было обнаружено повышение общей доли оплодотворенных яиц при использовании заморожено-оттаянного семени в группах Mal-10 (92,6 \%) и Mal$20(86,3 \%)$ по сравнению с группой ЛКС-контроль $(74,7 \%)$, а также увеличение продолжительности функциональной полноценности сперматозоидов в половых путях кур в течение 5 сут. По прогрессивной подвижности сперматозоидов (целостности кинетического аппарата) группы не различались, при этом функциональная полноценность, оцененная по числу взаимодействий с вителлиновой мембраной, существенно разнилась. Она была значительно выше при использовании

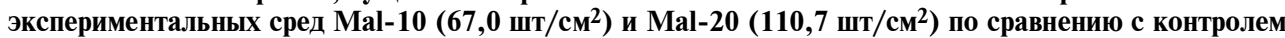
$(40,1$ шт/см²). Наилучшие показатели фертильности сперматозоидов отмечали в группе Mal-20: даже на 15-е сут после последнего осеменения оплодотворяющая способность заморожено-оттаянного семени составляла $20 \%$. Согласно составленному уравнению регрессии, для приемлемой оплодотворенности яиц (не менее 80 \%) достаточна такая функциональная полноценность заморожено-оттаянных сперматозоидов, при которой число точек взаимодействия с вителлиновой мембраной желтка составляет не менее 60 шт/см². Это было достигнуто при использовании экспериментального разбавителя с 0,326 г мальтозы на 100 мл. Полученные результаты открывают перспективы использования криоконсервированного семени птицы как для сохранения генофонда, так и в селекционных программах.

Ключевые слова: петухи, сперма, фертильность, криоконсервация, разбавитель, мальтоза, вителлиновая мембрана.

Криоконсервация семени птиц - важный и широко используемый метод длительного хранения репродуктивных клеток самцов, однако его

* Работа проведена в рамках выполнения научных исследований Министерства науки и высшего образования РФ по теме № АAАA-A18-118021590132-9.

1148 
эффективность в птицеводстве не столь высока, как в молочном скотоводстве, где он применяется для генетического улучшения пород. Поиск новых концепций и протоколов в криоконсервации семени петухов позволит создавать криобанки генетического материала не только как хранилище образцов редких и исчезающих пород, но и как рабочие резервно-страховые фонды репродуктивных клеток (1-3). Криоконсервация вызывает неблагоприятные изменения в сперматозоидах, что приводит к повреждению и тотальной гибели клеток и снижает качество спермы. Так, происходят частично необратимые повреждения морфологических структур клетки, нарушения структуры органелл, изменение биохимических процессов и надмембранной структуры - плотного углеводного слоя (гликокаликса) (4). Все перечисленные изменения сперматозоида и его эпигенетические модификации, связанные с метилированием ДНК, а также дефектом протаминизации и нарушением клеточных параметров, включая целостность мембраны, стабильность ДНК, активность митохондрий, становятся причинами снижения подвижности и фертильности сперматозоидов в процессе замораживания/оттаивания $(5,6)$.

Сохранение функциональной способности сперматозоидов птиц после размораживания зависит от видовой принадлежности, особенностей породы, композиционного состава среды для замораживания, включая криопротекторы, используемых процедур уравновешивания (balancing) спермы, а также протоколов замораживания и оттаивания. Кроме того, для успешной криоконсервации сперматозоидов важно стартовое качество свежей спермы (7).

Для получения высоких результатов при использовании заморожено-оттаянного семени петухов необходимо предотвратить повреждения, вызываемые кристаллизацией воды во время замораживания. Образование внутриклеточных кристаллов льда, особенно трехвекторная форма кристаллизации $(8,9)$, - одна из главных причин гибели клеток. Кроме того, исследователи ищут способы повышения фертильности криоконсервированного семени не только через протоколы замораживания и оттаивания (fast/slow) (10), но и посредством подбора оптимальных сред для криоконсервации. В состав таких сред входят антиоксиданты, которые нейтрализуют воздействие на клетки накопленного активного кислорода (1-карнитин, эллаговая кислота, цистеамин, эрготионеин, серин, каталаза) (11-14), а также энергетические компоненты (сахариды) (15), поддерживающие функциональность спермиев, в частности благодаря усилению конструкции гликокаликса (4). Присутствие компонентов, выполняющих дегидратационную функцию (сахариды, гиалуроновая кислота), позволяет оптимизировать внутриклеточное осмотическое давление (16-18). Протокол криоконсервации репродуктивных клеток подразумевает обязательное применение агентов-криопротекторов, оказывающих эндо- и экзоцеллюлярное $(19,20)$ либо комбинированное действие. Как правило, такие агенты используются непосредственно при создании криопротекторных сред, а также в сочетании с внешними криоагентами - глицерином, диметилсульфоксидом, диметилацетамидом $(21,22)$. В большинстве случаев при замораживании применяются среды Lake (P.E. Lake, J.M. Stewart, 1978), Beltsville (13) и ЛКС (Bceроссийский НИИ генетики и разведения сельскохозяйственных животных - ВНИИГРЖ, авторское свидетельство № 1130339 от 23.12.1984, Россия) для разбавления нативного семени петухов с добавлением необходимых компонентов.

По данным литературы, различное сочетание невосстанавливающих и восстанавливающих сахаров может обеспечить лучшую защиту семени в 
процессе замораживания/оттаивания (23). На разных видах животных оценено влияние сочетания моносахаридов (фруктозы, галактозы, глюкозы, ксилозы) и дисахаридов (лактозы, трегалозы, мальтозы, сахарозы) в составе разбавителей для криконсервации семени. При этом эффективность мальтозы в составе разбавителя для семени петухов практически не изучена, хотя ее потенциальное положительное действие показано на других видах животных $(24,25)$.

Исследования по криоконсервации семени петухов в основном проводят на 28-32-недельном поголовье $(10,17,26)$ и значительно реже на птице более старшего возраста, что, вероятно, связано со снижением репродуктивных качеств и эффективности криконсервации. Однако из-за тенденции к увеличению сроков продуктивного использования кур до 80 нед жизни возникает необходимость проведения опытов на петухах в возрасте от 46 нед.

В настоящей работе впервые доказана эффективность использования мальтозы в сочетании с фруктозой в составе разбавителя для повышения оплодотворяющей способности заморожено-оттаянного семени петухов.

Целью работы было определение оптимальной концентрации мальтозы в составе разбавителя для замораживания семени петухов в возрасте 44-50 нед и установление сроков сохранения функциональной полноценности заморожено-оттаянного семени в половых путях курицы.

Meтодика. Опыты проводили в 2020 году на птице (Gallus gallus L.) породы русская белая $(\stackrel{n}{n}=10, q n=30)$ в возрасте 44-50 нед, содержащейся в индивидуальных клетках в соответствии с технологией, принятой в ЦКП «Генетическая коллекция редких и исчезающих пород кур» (ВНИИГРЖ) (2020 год). Сперму собирали квалифицированные специалисты, попадание загрязнений в эякуляты было исключено или сведено до минимума. Сперму получали методом абдоминального массажа (27) дважды в неделю (использовали стеклянные флаконы объемом 10 мл) в течение 4 нед. Для индивидуальной оценки качества каждого эякулята применяли визуализирующую систему CASA (Computer-Assisted Semen Analysis; программное обеспечение Аргус-CASA, OOO «АргусСофт», Россия; микроскоп Motic $®$ BA310E, ×200, «Motic Instruments Inc.», Канада). Определяли объем эякулята (мл), концентрацию сперматозоидов (млрд/мл) (Accuread Photometer, «IMV Technologies», Великобритания), их общую и прогрессивную подвижность (\%), степень агглютинации (\%). Оценку осуществляли в 5 повторностях. Чтобы устранить индивидуальные различия между особями, образцы семени после каждой оценки объединяли и разделяли на три аликвоты по разработанному плану эксперимента. Исследование проведено в соответствии с принципами биоэтики согласно Европейской Конвенции о защите позвоночных животных, используемых для экспериментов или в иных научных целях (ETS 123, 1986 год, статья 5, глава 2).

Состав среды ЛКС-контроль (Ленинградская криозащитная среда) для замораживания спермы (28) был следующим (на 100 мл дистиллированной воды): глутамат натрия (1,92 г), фруктоза (0,8 г), ацетат калия $(0,5$ г), поливинилпирролидон (0,3 г), сульфат протамина $(0,032$ г). Для экспериментальных разбавителей Mal-10 и Mal-20 состав был рассчитан с частичной заменой фруктозы на мальтозу (соответственно 0,72 г фруктозы + 0,166 г мальтозы и 0,64 г фруктозы + 0,326 г мальтозы), остальные компоненты оставались без изменений.

Разбавленные образцы семени охлаждали от 18 до $5^{\circ} \mathrm{C}$ в течение 40 мин. Затем к каждому образцу добавляли диметилацетамид (dimethylacetamide, DMA,) («Sigma-Aldrich», США) до конечной концентрации $6 \%$. 
После добавления DMA образцы инкубировали при $5{ }^{\circ} \mathrm{C}$ в течение 1 мин. Гранулы замораживали, накапывая семя в жидкий азот. Исходное положение пипетки с семенем контролировалось ручным цифровым индикатором температуры с датчиком (AHLBORN ${ }^{\circledR}$ THERM 24201L, «Ahlborn Mess- und Regelungstechnik GmbH», Германия), в зоне размещения пипетки температура составляла $-15 \ldots-20^{\circ} \mathrm{C}$, на поверхности жидкого азота $-135^{\circ} \mathrm{C}$. Средняя скорость подачи семени в жидкий азот составляла 1,4 капли в секунду. Замороженное семя хранили в жидком азоте в сосудах Дьюара в течение 30 сут. Гранулы размораживали по fast-протоколу на нагреваемой металлической пластине при $60{ }^{\circ} \mathrm{C}$ (оборудование разработки ВНИИГРЖ, 1989 год).

Двигательную активность (общая и прогрессивная подвижность) заморожено-оттаянных сперматозоидов регистрировали в каждом экстендере с помощью визуализирующей системы CASA (Motic ${ }^{\circledR}$ BA310E, ×200). Каждый образец оценивали дважды.

Для искусственного осеменения отобрали виргинных кур в возрасте 46-50 нед ( $n=30$, по $n=10$ в каждой опытной группе). Кур осеменяли интравагинально разовыми суточными дозами 0,04-0,07 мл заморожено-оттаянного семени (не менее 70-80 млн активных, прогрессивно движущихся сперматозоидов) (29): в течение первых 2 сут по одному осеменению, затем одно осеменение каждые 2 сут. Время осеменения - после 1400 , общее число осеменений - 5. Яйца для инкубации собирали ежедневно в течение 9 сут, начиная со вторых суток после первого осеменения. Яйца $(n=239)$ инкубировали 6 сут для оценки фертильности.

Яйца, собранные в каждой экспериментальной группе на 5-е, 10-е и 15-е сут после последнего осеменения, разбивали и оценивали оплодотворенность по состоянию бластодиска.

Динамику функциональной активности заморожено-оттаянных сперматозоидов в половых путях кур на 5-е, 10-е, 15-е сут от последнего осеменения определяли по методике M. Bakst с соавт. (30) по числу отверстий в вителлиновой мембране желтка (размер выборки $n=55)$, образованных в результате взаимодействия со сперматозоидами. Желтки аккуратно отделяли от яичного белка. На желток в области бластодиска накладывали кольцо из фильтровальной бумаги, затем вырезали мембрану изогнутыми медицинскими ножницами с острым концом по внешнему диаметру кольца. Отделенную мембрану захватывали пинцетом и несколько раз промывали 0,9\% раствором $\mathrm{NaCl}$ при 4-5 ${ }^{\circ} \mathrm{C}$ до полного удаления желтка, затем аккуратно размещали на предметное стекло. Для лучшей визуализации препарат окрашивали в соответствии со следующим протоколом. На вителлиновую мембрану микропипеткой равномерно наносили 30 мкл спиртового $10 \%$ раствора формалина. Через 15-20 с формалин сливали и помещали на мембрану 30-40 мкл реактива Шиффа, используя микропипетку с наконечником, обернутым в алюминиевую фольгу (для минимизации попадания света на реактив Шиффа). После того как вителлиновая мембрана приобретала пурпурный оттенок ( 3 0 c), избыток реактива Шиффа отмывали дистиллированной водой, препараты высушивали на воздухе в течение 5 мин перед микроскопированием. Площадь внутри кольца фильтровальной бумаги $\left(\mathrm{S}=1 \mathrm{~cm}^{2}\right)$ определяли с помощью микроскопа Axio Imager («Carl Zeiss Microscopy $\mathrm{GmbH»,} \mathrm{Германия)} \mathrm{в} \mathrm{темном} \mathrm{поле} \mathrm{при} \mathrm{увеличении} \times 200$, подсчитывали число отверстий в вителлиновой мембране.

Для статистической обработки данных и регрессионного анализа использовали программные приложения Microsoft Excel 2013 и Statistica 7.0 («StatSoft, Inc.», США). Данные были представлены в виде средних зна- 
чений $(M)$ и стандартных ошибок средних ( \pm SEM). Выборки по оценке нативного семени соответствовали нормальному распределению Гаусса с параметрами $\chi^{2}$ теоритич. $=12,6>\chi^{2}$ эмпирич. $=6,5$ по показателям оценки объема спермы и подвижности сперматозоидов. Различия между выборками оценивали по $t$-критерию Стьюдента и считали достоверными при р $<0,05$.

Результаты. Общая подвижность свежеполученного семени в среднем составляла от 79,43 до 83,93 \%, доля сперматозоидов с прямолинейно поступательным движением - от 63,22 до 70,90 \% (табл. 1). Объем индивидуальных эякулятов в различные дни варьировал от 0,3 мл до 1,1 мл; концентрация сперматозоидов составляла не менее 3,2 млрд/мл, агглюцинация не превышала $10 \%$.

1. Средние показатели качества нативного семени, полученного от петухов (Gallus gallus L.) породы русская белая ( $n=50, M \pm \mathrm{SEM}$, ЦКП «Генетическая коллекция редких и исчезающих пород кур», ВНИИГРЖ, г. СанктПетербург-Пушкин, 2020 год)

\begin{tabular}{l|c|c|c}
\hline № петуха & Объем эякулята, мл & Общая подвижность, \% & Прогрессивная подвижность, \% \\
\hline 1 & $0,54 \pm 0,03$ & $82,88 \pm 2,50$ & $70,07 \pm 3,52$ \\
2 & $0,36 \pm 0,06$ & $79,43 \pm 5,30$ & $64,37 \pm 6,21$ \\
3 & $0,05 \pm 0,05$ & $83,93 \pm 1,27$ & $70,12 \pm 1,82$ \\
4 & $0,45 \pm 0,07$ & $83,93 \pm 1,05$ & $70,90 \pm 0,54$ \\
5 & $0,60 \pm 0,04$ & $78,25 \pm 5,39$ & $63,26 \pm 5,78$ \\
6 & $0,46 \pm 0,02$ & $81,35 \pm 2,41$ & $67,49 \pm 2,10$ \\
7 & $0,73 \pm 0,07$ & $81,15 \pm 1,17$ & $66,22 \pm 1,23$ \\
8 & $0,54 \pm 0,04$ & $82,85 \pm 2,44$ & $67,34 \pm 1,02$ \\
9 & $0,36 \pm 0,04$ & $81,45 \pm 1,48$ & $63,95 \pm 2,49$ \\
10 & $0,39 \pm 0,07$ & $82,83 \pm 2,18$ & $67,19 \pm 3,01$ \\
\hline
\end{tabular}

2. Показатели качества (min-max по датам опыта) заморожено-оттаянного семени петухов (Gallus gallus L.) породы русская белая и оплодотворенность яиц за первые 9 сут сбора в зависимости от состава среды для криоконсервации $(\delta n=10, q n=30$, ЦКП «Генетическая коллекция редких и исчезающих пород кур», ВНИИГРЖ, г. Санкт-Петербург-Пушкин, 2020 год)

\begin{tabular}{l|c|c|c|c}
\hline Разбавитель & Общая подвижность, $\%$ & $\begin{array}{c}\text { Прогрессивная } \\
\text { подвижность, } \%\end{array}$ & Число яиц, шт. & $\begin{array}{c}\text { Оплодотворенность } \\
\text { яиц, \% }\end{array}$ \\
\hline ЛКС-контроль & $51-54$ & $45-50$ & 83 & 74,7 \\
Mal-10 & $51-54$ & $45-50$ & 81 & 92,6 \\
Mal-20 & $51-54$ & $45-50$ & 75 & 86,3 \\
\hline \multicolumn{1}{l}{ П р и м е ч а н и е. Состав сред для замораживания спермы см. в разделе «Методика». }
\end{tabular}

Различия в функциональном состоянии заморожено-оттаянного семени петухов между контролем и опытом оценивали при искусственном осеменении кур с последующей инкубацией яиц. Показатели оплодотворенности яиц (табл. 2) различались в зависимости от состава разбавителя для криоконсервации семени. В группах Mal-10 и Mal-20 при использовании мальтозы в качестве компонента среды для криоконсервации отмечали существенное (на 11,6-17,9 \%) повышение оплодотворенности яиц по сравнению с контролем ( $<0,05)$. Однако отметим, что при исследовании заморожено-оттаянного семени методом оптической микроскопии мы не выявили различий между контрольной и экспериментальными группами по показателю активности и доле сперматозоидов с прямолинейно поступательным движением.

Наибольший процент оплодотворенности яиц на 5-е сут осеменения наблюдался в группе Mal-20 (100\% против 50 \% в группе ЛКС-контроль), на 10-е сут в группах Mal-10 и Mal-20 оплодотворенность составила соответственно 60 и $100 \%$ против $40 \%$ в контроле. На 15-е сут от последнего осеменения в группах ЛКС-контроль и Mal-10 не было получено оплодотворенных яиц, однако в группе Mal-20 их доля составляла 20 \% (рис. 1). 


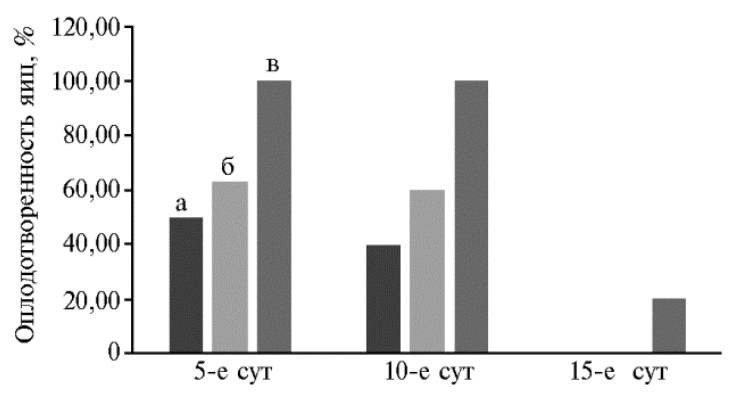

Рис. 1. Оплодотворенность яиц кур ( Gallus gallus L.) породы русская белая на 5-е, 10-е и 15-е сут от последнего осеменения в зависимости от состава среды для криоконсервации семени петухов: a ЛКС-контроль, б - Mal-10, в - Mal20 ; состав сред для замораживания спермы см. в разделе «Методика» $(n=55$, ЦКП «Генетическая коллекция редких и исчезающих пород кур», ВНИИГРЖ, г. Санкт-Петербург-Пушкин, 2020 год).

Определение числа точек взаимодействия сперматозоидов с вителлиновой мембраной желтка (рис. 2) показало, что функциональная способность сперматозоидов была значительно выше при использовании экспериментальных сред, содержащих мальтозу.
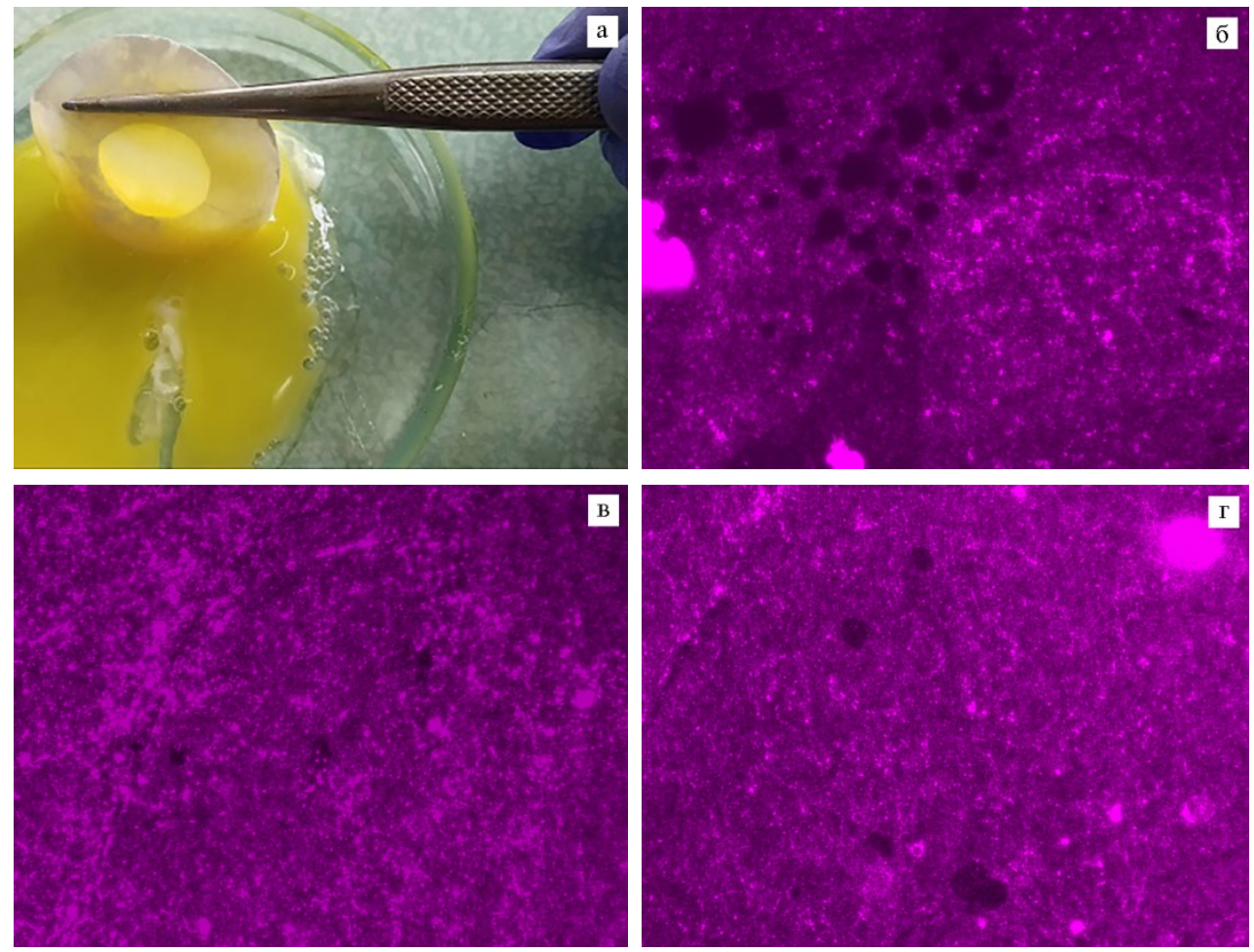

Рис. 2. Отверстия (темные точки), образовавшиеся при взаимодействии заморожено-оттаянных сперматозоидов петухов (Gallus gallus L.) породы русская белая с вителлиновой мембраной желтка при разном составе среды для криоконсервации семени: а - отделение вителлиновой мембраны; б - среда Mal-20, в - среда Mal-10, г - среда ЛКС-контроль (микроскоп Axio Imager, «Carl Zeiss Microscopy GmbH», Германия, увеличение $\times 200$; окрашивание реактивном Шиффа); состав сред для замораживания спермы см. в разделе «Методика» (ЦКП «Генетическая коллекция редких и исчезающих пород кур», ВНИИГРЖ, г. Санкт-Петербург-Пушкин, 2020 год).

Семя, разбавленное средой Mal-20, отличалось от остальных образцов повышенной жизнеспособностью в половых путях курицы: даже на 15-е сут от последнего осеменения число точек взаимодействия сперматозоидов с вителлиновой мембраной в группе Mal-20 было на 45,8 \% выше, чем в контроле (табл. 3).

Для выявления зависимости между числом точек взаимодействия сперматозоидов с вителлиновой мембраной желтка и оплодотворенностью яиц было составлено уравнение регрессии и определен коэффициент 
аппроксимации (рис. 3). Полученный в группе Mal-20 результат подтверждался положительной линейной зависимостью (достоверность уравнения регрессии определена по коэффициенту детерминации $\mathrm{R}^{2}=0,88$ ) двух признаков на отрезке изменчивости переменной Y, где переменная X принимала значения от 10 до 80 . На участке кривой, где $\mathrm{X}$ принимала значения $>80$, величина переменной Y была постоянной.

3. Число взаимодействий (шт/см²) заморожено-оттаянных сперматозоидов петухов (Gallus gallus L.) породы русская белая с вителлиновой мембраной желтка яиц в зависимости от состава среды для криоконсервации семени ( $n=55$, $M \pm \mathrm{SEM}$, ЦКП «Генетическая коллекция редких и исчезающих пород кур», ВНИИГРЖ, г. Санкт-Петербург-Пушкин, 2020 год)

\begin{tabular}{|c|c|c|c|}
\hline \multirow{2}{*}{ Разбавитель } & \multicolumn{3}{|c|}{ Время от последнего осеменения, сут } \\
\hline & $5-e$ & $10-\mathrm{e}$ & $15-e$ \\
\hline ЛКС-контроль & $40,1 \pm 17,9^{a}$ & $36,4 \pm 15,2$ & $26,6 \pm 6,1$ \\
\hline Mal-10 & $67,0 \pm 5,5$ & $67,0 \pm 18,7$ & $27,8 \pm 5,8$ \\
\hline Mal-20 & $110,7 \pm 15,8^{b}$ & $86,7 \pm 28,2$ & $38,8 \pm 21,8$ \\
\hline
\end{tabular}

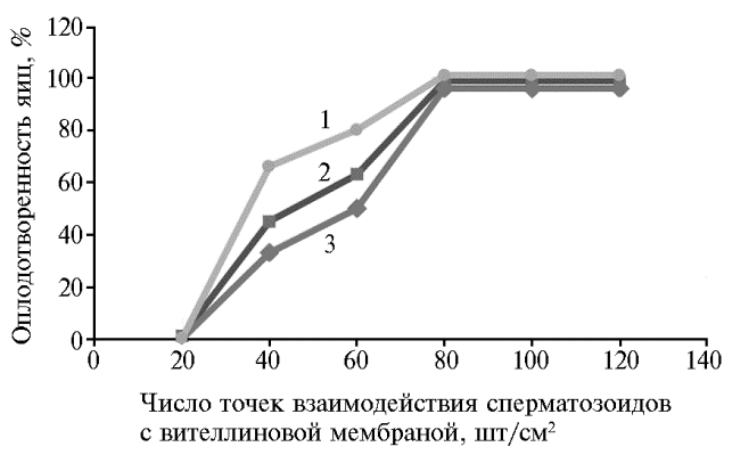

Рис. 3. Связь между числом точек взаимодействия заморожено-оттаянных сперматозоидов петухов (Gallus gallus L.) породы русская белая с вителлиновой мембраной желтка и оплодотворенностью яиц в зависимости от состава среды для криоконсервации семени: $1-$ Mal-20 (y = 1,585x - 17,5, $\left.\mathrm{R}^{2}=0,8807\right), 2-$ Mal-10 $\left(\mathrm{y}=1,585 \mathrm{x}-28,5, \mathrm{R}^{2}=0,9913\right)$, 3 - ЛКС-контроль ( $\left.\mathrm{y}=1,525 \mathrm{x}-31,5, \mathrm{R}^{2}=0,9701\right)$; состав сред для замораживания спермы см. в разделе «Методика» (ЦКП «Генетическая коллекция редких и исчезающих пород кур», ВНИИГРЖ, г. Санкт-Петербург-Пушкин, 2020 год). ной мембраны. Гликокаликс, усиленный растворенными в среде для криоконсервации семени петухов дисахаридами, стабилизирует мембраны сперматозоидов и не только работает как криоустойчивая структура, но и повышает сроки сохранения функциональной полноценности сперматозоидов в половых путях курицы. По данным Е. Tecle и P. Gagneux (32), гликокаликс сперматозоидов опосредует многочисленные функции женского репродуктивного тракта, в том числе защиту от врожденного и адаптивного женского иммунитета, и осуществляет маскировку белков спермы, участвующих в оплодотворении. Гликокаликс сперматозоидов модифицируется во время их движения в половых путях курицы и нахождения в криптах и представляет собой первичный интерфейс между мужской гаметой и окружающей средой (33).

Сахариды (сахароза, лактоза, трегалоза, глюкоза, фруктоза) использовались как энергетические источники и криопротекторы в качестве 
компонентов разбавителя семени при криоконсервации сперматозоидов различных животных (собаки, японские черные медведи, козы, красная джунглевая курица) (34-37). Изучение строения и свойств дисахарида мальтозы (38) дает основание прогнозировать ее успешное использование в комбинации с моносахаридом в составе разбавителя для криоконсервации семени петухов. Величина молекулы мальтозы не позволяет преодолеть клеточную мембрану, кроме того, этот дисахарид обладает низкой скоростью ферментирования (39) и может усиливать «сахарную шубу» на конструкции гликокаликса. Анализ доступных публикаций показал, что мальтоза до настоящего времени не применялась в качестве компонента среды для криоконсервации семени петухов. При криоконсервации семени осетровых рыб использование мальтозы было равно успешным с другими дисахаридами (лактоза, трегалоза и лактулоза) (40). При добавлении в разбавитель для нативного семени петухов мальтоза в незначительной степени включается в углеводный обмен сперматозоидов (41). Следовательно, можно предположить, что она присоединяется к гликокаликсу - эволюционно прогрессивной структуре, которая обеспечивает клетке способность специфически адаптироваться к температурному, химическому и другим паратипическим воздействиям.

В нашем эксперименте не ставилась задача исследовать клеточные механизмы влияния состава экспериментальных сред на жизнеспособность сперматозоидов, но некоторые гипотезы могут быть предложены. Мальтоза и фруктоза в составе сред Mal-10 и Mal-20 в сочетании с DMA по влиянию на защитные свойства клетки при низких температурах представляют комбинацию из трех криопротекторов проникающего и непроникающего действия. DMA - криопротектор амидной группы, способствующий формированию водородных связей, что создает условия для образования соединений, препятствующих кристаллизации воды. Фруктоза как незначительная молекулярная единица свободно проникает сквозь мембрану в плазму клетки и функционирует и как энергетическая структура, и как компонент, снижающий осмотическую нагрузку на мембрану в процессе замораживания/оттаивания. Мальтоза, по нашему предположению, фиксируется на надмембранной оболочке (гликокаликсе) клетки, создавая более прочный углеводный каркас, защищающий клетку от холодовых ударов, и предупреждает его разрушение. Вся эта система компонентов позволяет максимально снизить негативное воздействие процессов замораживания и оттаивания на сперматозоиды и поддерживать их функциональную полноценность непосредственно в половом тракте курицы, поскольку целостность гликокаликса сперматозоида становится критическим фактором при взаимодействии с гаметами кур (4).

Таким образом, было продемонстрировано повышение общей оплодотворенности яиц кур при осеменении заморожено-оттаянным семенем, если в качестве компонента среды для замораживания спермы петухов использовалась мальтоза. При добавлении в состав разбавителя 0,166 и 0,326 г мальтозы на 100 мл оплодотворенность яиц составляла соответственно 92,6 и 86,3 \%, в контроле - 74,7 \%. Кроме того, в половых путях курицы сперматозоиды сохраняли функциональную полноценность в течение 5 сут, что сопоставимо с показателями при использовании нативного семени для искусственного осеменения. Показатели прогрессивной подвижности, характеризующие целостность кинетического аппарата сперматозоидов, между группами не различались, но при этом функциональная полноценность спермиев, оцененная по числу взаимодействий с вител- 
линовой мембраной, существенно разнилась. Для приемлемой оплодотворенности яиц (не менее 80 \%) достаточна такая функциональная полноценность заморожено-оттаянных сперматозоидов, при которой число точек взаимодействия с вителлиновой мембраной желтка составляет не менее 60 шт/см². Это было достигнуто при использовании экспериментального разбавителя с мальтозы в концентрации 0,326 \%. Полученные результаты открывают перспективы для использования криоконсервированного семени птиц не только в программах сохранения генофонда, но и в селекции.

\section{ЛИТЕРАТУРА}

1. Thélie A., Bailliard A., Seigneurin F., Zerjal T., Tixier-Boichard M., Blesbois E. Chicken semen cryopreservation and use for the restoration of rare genetic resources. Poultry Science, 2018, 98(1): 447-455 (doi: 10.3382/ps/pey360).

2. Силюкова Ю., Станишевская О., Дементьева Н. Современное состояние проблемы сохранения генетических ресурсов сельскохозяйственных птиц in vitro. Вавиловский журнал генетики и селекции, 2020, 24(2): 176-184 (doi: 10.18699/VJ20.611).

3. Di Iorio M., Rusco G., Iampietro R., Colonna M.A., Zaniboni L., Cerolini S., Iaffaldano N. Finding an effective freezing protocol for turkey semen: benefits of ficoll as non-permeant cryoprotectant and 1:4 as dilution rate. Animals, 2020, 10(3): 421 (doi: 10.3390/ani10030421).

4. Peláez J., Long J.A. Characterizing the glycocalyx of poultry spermatozoa: II. In vitro storage of Turkey semen and mobility phenotype affects the carbohydrate component of sperm membrane glycoconjugates. Journal of Andrology, 2008, 29(4): 431-439 (doi: 10.2164/jandrol.107.004259).

5. Salehi M., Mahdavi A.H., Sharafi M., Shahverdi A. Cryopreservation of rooster semen: evidence for the epigenetic modifications of thawed sperm. Theriogenology, 2020, 142: 15-25 (doi: 10.1016/j.theriogenology.2019.09.030).

6. Silyukova Y., Pleshanov N., Stanishevskaya O. The influence membranes damage and activity of roosters' sperm on the fertilization of eggs when using cured cryopreserved sperm. Reproduction in Domestic Animals, 2019, 54(S3): 101 (doi: 10.1111/rda.13528).

7. Partyka A., Łukaszewicz E., Niżański W. Flow cytometric assessment of fresh and frozenthawed Canada goose (Branta canadensis) semen. Theriogenology, 2011, 76(5): 843-850 (doi: 10.1016/j.theriogenology.2011.04.016).

8. Huebinger J., Han H.-M., Hofnagel O., Vetter I.R., Bastiaens P.I.H., Grabenbauer M. Direct measurement of water states in cryopreserved cells reveals tolerance toward ice crystallization. Biophysical Journal, 2016, 110(4): 840-849 (doi: 10.1016/j.bpj.2015.09.029).

9. Askarianzadeh Z., Sharafi M., Torshizi M.A.K. Sperm quality characteristics and fertilization capacity after cryopreservation of rooster semen in extender exposed to a magnetic field. Animal Reproduction Science, 2018, 198: 37-46 (doi: 10.1016/j.anireprosci.2018.08.043).

10. Zaniboni L., Cassinelli C., Mangiagalli M.G., Gliozzi T.M., Cerolini S. Pellet cryopreservation for chicken semen: effects of sperm working concentration, cryoprotectant concentration, and equilibration time during in vitro processing. Theriogenology, 2014, 82(2): 251-258 (doi: 10.1016/j.theriogenology.2014.04.007).

11. Fattah A., Sharafi M., Masoudi R., Shahverdi A., Esmaeili V., Najafi A. L-Carnitine in rooster semen cryopreservation: flow cytometric, biochemical and motion findings for frozen-thawed sperm. Cryobiology, 2017, 74: 148-153 (doi: 10.1016/j.cryobiol.2016.10.009).

12. Amini M.R., Kohram H., Zare-Shahaneh A., Zhandi M., Sharideh H., Nabi M.M. The effects of different levels of catalase and superoxide dismutase in modified Beltsville extender on rooster postthawed sperm quality. Cryobiology, 2015, 70(3): 226-232 (doi: 10.1016/j.cryobiol.2015.03.001).

13. Najafi A., Taheri R.A., Mehdipour M., Farnoosh G., Martínez-Pastor F. Lycopene-loaded nanoliposomes improve the performance of a modified Beltsville extender broiler breeder roosters. Animal Reproduction Science, 2018, 195: 168-175 (doi: 10.1016/j.anireprosci.2018.05.021).

14. Thananurak P., Chuaychu-noo N., Thélie A., Phasuk Y., Vongpralub T., Blesbois E. Different concentrations of cysteamine, ergothioneine, and serine modulate quality and fertilizing ability of cryopreserved chicken sperm. Poultry Science, 2020, 99(2): 1185-1198 (doi: 10.1016/j.psj.2019.10.040).

15. Thananurak P., Chuaychu-Noo N., Thélie A., Phasuk Y., Vongpralub T., Blesbois E. Sucrose increases the quality and fertilizing ability of cryopreserved chicken sperms in contrast to raffinose. Poultry Science, 2019, 98(9): 4161-4171 (doi: 10.3382/ps/pez196).

16. Lotfi S., Mehri M., Sharafi M., Masoudi R. Hyaluronic acid improves frozen-thawed sperm quality and fertility potential in rooster. Animal Reproduction Science, 2017, 184: 204-210 (doi: 10.1016/j.anireprosci.2017.07.018).

17. Donoghue A.M., Wishart G.J. Storage of poultry semen. Animal Reproduction Science, 2000, 62(13): 213-232 (doi: 10.1016/s0378-4320(00)00160-3).

18. Mavrodina T., Stanishevskaya O., Cherepanov S., Silyukova Y. Influence of osmolality of the 
media for dilution and cryopreservation of turkey toms' sperm on fertilization ability of thawed sperm. Reproduction in Domestic Animals, 2018, 53(Suppl. 2): 164.

19. Gloria A., Toscani T., Robbe D., Parrillo S., De Amicis I., Contri A. Cryopreservation of turkey spermatozoa without permeant cryoprotectants. Animal Reproduction Science, 2019, 211: 106-218 (doi: 10.1016/j.anireprosci.2019.106218).

20. Shahverdi A., Sharafi M., Gourabi H., Yekta A.A., Esmaeili V., Sharbatoghli M., Janzamin E., Hajnasrollahi M., Mostafayi F. Fertility and flow cytometric evaluations of frozen-thawed rooster semen in cryopreservation medium containing low-density lipoprotein. Theriogenology, 2015, 83(1): 78-85 (doi: 10.1016/j.theriogenology.2014.07.044).

21. Mosca F., Madeddu M., Sayed A.A., Zaniboni L., Iaffaldano N., Cerolini S. Data on the positive synergic action of dimethylacetamide and trehalose on quality of cryopreserved chicken sperm. Data in Brief, 2019, 9: 1118-1121 (doi: 10.1016/j.dib.2016.11.059).

22. Menezes G.F.O., Bittencourt R.F., Ribeiro Filho A.L., Cardoso F.L., Silva M.A.A., Santos E.S. Dimetilacetamida associada ou não ao glicerol para criopreservação de sêmen ovino [Dimethylacetamide associated or not to glycerol for criopreservation of sheep semen]. Ciência Animal Brasileir, 2018, 19: e-48026 (doi: 10.1590/1809-6891v19e-48026).

23. Xi M.D., Li P., Du H., Qiao X.M., Liu Z.G., Wei Q.W. Disaccharide combinations and the expression of enolase 3 and plasma membrane $\mathrm{Ca}^{2+}$ ATPase isoform in sturgeon sperm cryopreservation. Reproduction in Domestic Animals, 2018, 53(2): 472-483 (doi: 10.1111/rda.13134).

24. Yildiz C., Kaya A., Aksoy M., Tekeli T. Influence of sugar supplementation of the extender on motility, viability and acrosomal integrity of dog spermatozoa during freezing. Theriogenology, 2000, 54(4): 579-585 (doi: 10.1016/S0093-691X(00)00373-3).

25. Golshahi K., Aramli M.S., Nazari R.M., Habibi H. Disaccharide supplementation of extenders is an effective means of improving the cryopreservation of semen in sturgeon. Aquaculture, 2018, 486: 261-265 (doi: 10.1016/j.aquaculture.2017.12.045).

26. Khiabani A.B., Moghaddam G., Kia H.D. Effects of adding different levels of glutamine to modified Beltsville extender on the survival of frozen rooster semen. Animal Reproduction Science, 2017, 184: 172-177 (doi: 10.1016/j.anireprosci.2017.07.013)

27. Burrows W.A., Quinn J. P. A method of obtaining spermatozoa from the domestic fowl. Poultry Science, 1935, 14(4): 251-254.

28. Целютин К.В., Тур Б.К. Искусственное осеменение и криоконсервация спермы сельскохозяйственной птицы (петухи, индюки, гусаки, селезни). СПб-Пушкин, 2013.

29. Попов И.И. Вопросы искусственного осеменения домашних птиц. СПб-Пушкин, 2000.

30. Bakst M., Eastridge J., Malecki I. The inner perivitelline layer sperm hole assay: use of filter paper rings for the isolation of the perivitelline layer overlying the germinal disc and new observations on its morphology. Journal of Applied Poultry Research, 2014, 23(1): 121-128 (doi: 10.3382/japr.2013-00873).

31. Pleshanov N., Stanishevskaya O. Evaluation of the cocks spermatozoa membranes' damaging during cryopreservation with use of Sperm VitalStain colorant. Reproduction in Domestic Animals, 2018, 53(S2): 183.

32. Tecle E., Gagneux P. Sugar-coated sperm: unraveling the functions of the mammalian sperm glycocalyx. Mol. Reprod. Dev., 2015, 82(9): 635-650 (doi: 10.1002/mrd.22500).

33. Long J.A. Avian semen cryopreservation: what are the biological challenges? Poultry Science, 2006, 85(2): 232-236 (doi: 10.1093/ps/85.2.232).

34. Ponglowhapan S., Essén-Gustavsson B., Forsberg C.L. Influence of glucose and fructose in the extender during long-term storage of chilled canine semen. Theriogenology, 2004, 62(8): 14981517 (doi: 10.1016/j.theriogenology.2004.02.014).

35. Okano T., Murase T., Yayota C., Komatsu T., Miyazawa K., Asano M., Tsubota T. Characteristics of captive Japanese black bears (Ursus thibetanus japonicus) semen collected by electroejaculation with different voltages for stimulation and frozen-thawed under different conditions. Animal Reproduction Science, 2006, 95(1-2): 134-143 (doi: 10.1016/j.anireprosci.2005.10.002).

36. Naing S.W., Wahid H., Mohd Azam K., Rosnina Y., Zuki A.B., Kazhal S., Bukar M.M., Thein M., Kyaw T., San M.M. Effect of sugars on characteristics of Boer goat semen after cryopreservation. Animal Reproduction Science, 2010, 122(1-2): 23-28 (doi: 10.1016/j.anireprosci.2010.06.006).

37. Rakha B.A., Ansari M.S., Akhter S., Akhter A., Blesbois E., Santiago-Moreno O. Effect of dimethylformamide on sperm quality and fertilizing ability of Indian red jungle fowl (Gallus gallus murghi). Theriogenology, 2020, 149: 55-61 (doi: 10.1016/j.theriogenology.2020.03.023).

38. Феофилова Е.П., Усов А.И., Мысякина И.С., Кочкина Г.А. Трегалоза: особенности химического строения, биологические функции и практическое значение. Микробиология, 2014, 83(3): 271-283 (doi: 10.7868/S0026365614020074).

39. Ganatsios V., Koutinas A.A., Bekatorou A., Kanellaki M., Nigam P. Promotion of maltose fermentation at extremely low temperatures using a cryotolerant Saccharomyces cerevisiae strain immobilized on porous cellulosic material. Enzyme and Microbial Technology, 2014, 66: 56-59 (doi: 10.1016/j.enzmictec.2014.08.007).

40. Golshahi K., Aramli M.S., Nazari R.M., Habibi E. Disaccharide supplementation of extenders is an effective means of improving the cryopreservation of semen in sturgeon. Aquaculture, 2018, 
486: 261-265 (doi: 10.1016/j.aquaculture.2017.12.045).

41. Harris C.C., Wilcox F.H. The carbohydrate metabolism of chicken semen. Poultry Science, 1962 , 41(2): 409-416 (doi: 10.3382/ps.0410409).

Всероссийский НИИ генетики и разведения

Поступила в редакцию

сельскохозяйственных животных, филиал ФГБНУ ФИЦ животноводства 10 сентября 2020 года

\title{
ВИЖ им. академика Л.К. Эрнста,
}

196601 Россия, г. Санкт-Петербург-Пушкин, Московское ш., 55А,

e-mail: svadim33@mail.ru $₫$, olgastan@list.ru, Klaus-90@list.ru,

kurochkin.anton66@gmail.com

Sel'skokhozyaistvennaya biologiya [Agricultural Biology], 2020, V. 55, № 6, pp. 1148-1158

\section{EFFICIENCY OF USING A COMBINATION OF MONO- AND DISACCHARIDES IN A DILUENT FOR FREEZING ROOSTER SEMEN}

\author{
Yu.I. Silyukova ${ }^{凶}$, O.I. Stanishevskaya, N.V. Pleshanov, A.A. Kurochkin
}

All-Russian Research Institute for Farm Animal Genetics and Breeding - Branch of Ernst Federal Science Center for Animal Husbandry, 55A, Moskovskoe sh., pos. Tyarlevo, St. Petersburg-Pushkin, 196625 Russia, e-mail svadim33@mail.ru (₫ corresponding author), olgastan@list.ru, Klaus-90@list.ru, kurochkin.anton66@gmail.com ORCID:

Silyukova Yu.L. orcid.org/0000-0003-1905-6373

Stanishevskaya O.I. orcid.org/0000-0001-9504-3916

Pleshanov N.V. orcid.org/0000-0002-4634-7515

The authors declare no conflict of interests

Acknowledgements:

Research conducted on the topic AAAA-A18-118021590132-9.

Received September 10, 2020

doi: 10.15389/agrobiology.2020.6.1148eng

\section{Abstract}

Different combination of saccharides can provide better semen protection during freezing/thawing cycle. Until now, the disaccharide maltose has not been used as a component of the medium for cryopreservation roosters' semen. Since maltose is not involved in carbohydrate metabolism of spermatozoa, there is an assumption about its role in strengthening the structure of the glycocalyx, which is a progressive evolutionary cellular structure that regulates specific cellular adaptations to a certain temperature, chemical and other paratypical effects. In this work, in order to increase the fertility of frozen/thawed semen, we tested a combination of saccharides in the diluent for cryopreservation of roosters' semen. For the first time, maltose has been proven to be effective in combination with fructose in a diluent to increase the fertility of frozen/thawed roosters' semen. The aim of the study was to determine the optimal concentration of the test component of maltose based on the diluent of the Leningrad Cryoprotective Medium (LCM) (1984) for freezing the semen of roosters and determining the time of maintaining the functional usefulness of frozen/thawed cock semen in the genital tract of the hen. The experiment was carried out in the Center for Collective Use Genetic collection of rare and endangered chicken breeds (the Russian Research Institute of Farm Animal Genetics and Breeding, 2020) on a breed of Russian white chickens $(\delta n=10,9 n=30)$ at the age of 46-50 weeks. Three variants of media for cryopreservation of roosters' semen with different ratios of saccharides were evaluated. In each group, the Mal-10 (fructose 0.72 \%, maltose 0.166 \%), Mal-20 (fructose $0.64 \%$, maltose $0.326 \%$ ) and LCS-control (fructose $0.8 \%$, maltose $0 \%$ ), there were 10 hens for insemination. The results show not only an increase in the total percentage of fertilized eggs when using frozen/thawed semen in the Mal-10 (92.6\%) and Mal-20 (86.3\%) groups compared to the LKS-control group $(74.7 \%)$, but also an increase in the duration of the functional usefulness of spermatozoa in the genital tract of hen within 5 days at the level of native sperm. Counting the points of interaction of spermatozoa with the perivitelline membrane of the yolk 5 days after the last insemination showed that the functional ability of spermatozoa is much higher when using experimental media containing maltose, $67.0 \mathrm{pcs} / \mathrm{cm}^{2}$ for Mal-10 and $110.7 \mathrm{pcs} / \mathrm{cm}^{2}$ for Mal-20 vs. $40.1 \mathrm{pcs} / \mathrm{cm}^{2}$ in maltose-free LKS-control. The longest duration of the functional usefulness of spermatozoa was noted in the Mal-20 group. Even on day 15 after the last insemination, the fertilization capacity of frozen/thawed semen was recorded at the level of $20 \%$. A regression equation was drawn up for the relationship of egg fertilization with the points of interaction of spermatozoa with the perivitelline membrane of the yolk. To obtain an egg fertilization level of $\geq 80 \%$, the functional usefulness of frozen-thawed spermatozoa (expressed through the number of points of interaction with the perivitelline membrane of the yolk) should be $\geq 60 \mathrm{pcs} / \mathrm{cm}^{2}$. This was achieved by using an experimental diluent with $0.326 \%$ maltose. The results obtained open up the possibility of using cryopreserved semen not only in preserving the gene pool, but also in breeding programs.

Keywords: roosters, semen, fertility, cryopreservation, media, maltose, perivitelline membrane. 